19 Revue d'histoire du XIXe siècle

Société d'histoire de la révolution de 1848 et des

révolutions du XIXe siècle

$55 \mid 2017$

Les écoles du peuple à l'ère des révolutions

(1815-1880)

\title{
"L'éducation industrielle et les savoirs enseignés aux ouvriers adultes en France (1800-1870) »
}

Dossier coordonné par Carole CHRISTEN, Les Études sociales, $\mathrm{n}^{\circ} 159$, 2014/2, $180 \mathrm{p}$.

François Jarrige

\section{OpenEdition}

\section{Journals}

Édition électronique

URL : http://journals.openedition.org/rh19/5354

DOI : $10.4000 /$ rh 19.5354

ISSN : $1777-5329$

Éditeur

La Société de 1848

Édition imprimée

Date de publication : 1 décembre 2017

Pagination : 216-218

ISSN : 1265-1354

Référence électronique

François Jarrige, « «L'éducation industrielle et les savoirs enseignés aux ouvriers adultes en France (1800-1870) » », Revue d'histoire du XIXe siècle [En ligne], 55 | 2017, mis en ligne le 01 décembre 2017 consulté le 05 janvier 2021. URL : http://journals.openedition.org/rh19/5354 ; DOI : https://doi.org/ $10.4000 /$ rh19.5354

Ce document a été généré automatiquement le 5 janvier 2021.

Tous droits réservés 


\section{« L'éducation industrielle et les savoirs enseignés aux ouvriers adultes en France (1800-1870) »}

Dossier coordonné par Carole CHRISTEN, Les Études sociales, $\mathrm{n}^{\circ} 159$, 2014/2, $180 \mathrm{p}$.

François Jarrige

\section{RÉFÉRENCE}

«L'éducation industrielle et les savoirs enseignés aux ouvriers adultes en France (1800-1870) », dossier coordonné par Carole CHRISTEN, Les Études sociales, $n^{\circ} 159$, 2014/2, $180 \mathrm{p}$.

Dans ce riche numéro de la revue Les Études Sociales publié en 2014, dans la foulée d'une journée d'étude organisée à l'université de Lille 3, Carole Christen poursuit l'exploration des expériences réformatrices et éducatives à destination des classes populaires au XIXe siècle. Ce vaste chantier recoupe plusieurs traditions historiographiques qui s'ignorent souvent : l'étude des expériences émancipatrices par l'éducation dans la foulée notamment des travaux de Jacques Rancière sur l'autodidaxie; l'histoire de l'éducation au sens strict qui s'est de plus en plus développée et institutionnalisée ces dernières décennies; et enfin l'étude du paternalisme sous sa forme éducative. D'emblée est soulignée la difficulté de définir ce que recouvrent «l'éducation industrielle » et les ouvriers au XIX ${ }^{e}$ siècle, catégories floues qui renvoient à des situations très diverses et hétérogènes. Pourtant la question est importante tant la période 1800-1870 voit se transformer en profondeur l'enseignement comme les mondes du travail alors que s'engage le double mouvement d'élargissement de la souveraineté populaire et d'expansion industrielle. Évoquer «l'éducation industrielle » à destination des ouvriers adultes, c'est par ailleurs aller audelà de l'étude de l'enseignement professionnel et technique au sens strict, qui a suscité 
divers travaux récents. Il s'agit bien de penser les enjeux politiques et moraux de l'éducation, d'explorer comment s'opère l'acculturation aux nouvelles valeurs bourgeoises et libérales portées par les élites philanthropiques, et comment le "peuple» y répond en cherchant la voie d'une autre éducation émancipatrice. En croisant les discours et les pratiques à partir de terrains variés en France, l'enjeu de ce numéro est en définitive de proposer une histoire sociale et politique du projet d'éducation des ouvriers adultes tel qu'il a existé au XIX'e siècle.

2 La première partie est consacrée à la mise en place de l'éducation industrielle avant 1848 et à l'examen de quelques discours jugés fondateurs. La première contribution, de Corinne Doria, recherche ainsi les "origines intellectuelles $\mathrm{du}$ "paternalisme industriel" " dans le domaine éducatif à travers les écrits et discours des physiocrates et des industriels-philanthropes de la Société d'encouragement pour l'industrie nationale. Les deux contributions suivantes, de Gérard Bodé et François Vatin, reviennent sur les figures essentielles de Charles Dupin et Claude-Lucien Bergery et les expériences de cours pour les ouvriers qu'ils initient sous la Restauration. Au cours des années 1820, les polytechniciens libéraux Dupin et Bergery envisagent en effet une réforme de l'instruction publique qu'ils veulent davantage tournée vers les sciences et les savoirs industriels. Même si ces initiatives s'essoufflent rapidement et disparaissent au milieu des années 1830, elles ont joué un rôle important et ont largement préparé le terrain à la loi Guizot de 1833. Carole Christen complète ce tableau des précurseurs et expériences fondatrices en examinant les positions du journal ouvrier L'Atelier dans les années 1840. Elle montre ainsi une autre matrice, émanant de certaines franges du monde du travail, de cette aspiration éducative. Dans la lignée des utopies pédagogiques révolutionnaires et des projets de Joseph Jacotot, les artisans urbains de l'Atelier formulent une vive critique des initiatives philanthropiques des ingénieurs polytechniciens et militent pour une forme d'éducation capable de forger des citoyens libres. Un deuxième ensemble de contributions explore ensuite la «formalisation des savoirs enseignés aux ouvriers" à travers quelques expériences concrètes d'enseignement. Renaud d'Enfert revient ainsi sur l'offre d'enseignements mathématiques en montrant les complémentarités qui existaient entre les enseignements de géométries et de mécaniques et ceux de dessin ; Matthieu de Oliveira explore quant à lui les enjeux et objectifs d'un enseignement de comptabilité à destination des ouvriers alors que s'étend la fonction comptable et gestionnaire dans les organisations. Fabien Knittel examine ensuite un type singulier d'enseignement agricole à travers l'expérience de l'apprentissage des savoir-faire dans les fruitières de Franche-Comté, associations coopératives dédiées à la production de fromages. Stéphane Lembré termine ce parcours en présentant l'éphémère «Société d'enseignement mutuel des travailleurs de Roubaix» (1869-1872) initiée par un modeste filateur de la ville mais rapidement dénoncée par le reste du patronat local qui y voyait une menace subversive dans le contexte troublé qui entoure la Commune de Paris.

3 On aimerait évidemment en savoir encore plus sur la réception de ces expériences, sur la fréquentation réelle et la sociologie des publics, ou sur le type de savoirs dispensés, mais les sources manquent souvent pour approcher au plus près ces diverses expériences et leurs significations. Les études réunies ici montrent en tout cas une fois de plus combien l'histoire de l'éducation à destination du peuple ne démarre pas avec les réformes républicaines de Jules Ferry mais s'enracine dans un temps long marqué 
par les expériences révolutionnaires successives, par les besoins de s'adapter à une industrie perturbatrice, et par les aspirations réformatrices multiples qui naissent au cours du siècle. Par-delà les situations singulières exposées dans chaque texte, tous les articles montrent également la mise en place précoce d'une tension et de luttes entre plusieurs visions possibles de l'éducation: une conception modernisatrice soucieuse d'accompagner l'industrialisation en forgeant une main-d'œuvre adaptée ; une autre plus moralisatrice cherchant à inculquer ordre et discipline à des classes ouvrières qui inquiètent; et une approche émancipatrice et réformatrice voyant dans l'éducation un levier d'action pour égaliser les conditions et résoudre la question sociale. Cette tension ne disparait évidemment pas après 1870 , elle ne cesse de se rejouer depuis et d'animer les querelles autour de l'école, de la pédagogie, et de leurs réformes. 